Artículo de investigación

Cuestiones de Filosofía

ISSN: 0123-5095

E-ISSN: 2389-9441

Vol. $3-\mathrm{N}^{\circ} 21$

Junio - diciembre, año 2017

pp. $67-86$

\title{
Estado nacional, globalización y democracia
}

National State, Globalization, and Democracy

Wilson Alcides Valenzuela-Pérez

Universidad Pedagógica y Tecnológica de Colombia

Recepción: 8 de mayo del 2017

Evaluación: 1 de junio del 2017

Aceptación: 4 de octubre del 2017

Estado nacional, globalización y democracia,

Wilson Alcides Valenzuela-Pérez - p. 67-86 


\title{
Resumen
}

La definición de Estado nacional que Hans Kelsen expone en su obra clásica del pensamiento jurídico Teoría general del Derecho y del Estado lo caracteriza como organización política, que crea una comunidad nacional con el objeto de ejercer el poder político en el marco de un orden normativo válido para un espacio territorial delimitado, mediante el cual, se garantiza el principio de autodeterminación de un pueblo y su complemento necesario: la soberanía. Sin embargo, con motivo de los procesos de globalización, en particular, globalización de la economía de mercado, las decisiones más importantes que afectan al Estado se toman en los organismos económicos internacionales como el Fondo Monetario Internacional o el Banco Mundial, con lo cual, los principios de autodeterminación y de soberanía propios de la clásica definición del Estado nacional son puestos en cuestión y se han convertido en una mera ficción. Ante esa realidad, la idea de una sociedad cosmopolita, postulada por Kant hace ya más de doscientos años, retoma su vigencia, salvo que ahora, a la distancia histórica, la propuesta kantiana debe ser implementada por la democratización de los procesos de constitución de un nuevo orden mundial. El presente artículo explora la posibilidad de fortalecer la democracia gracias a una reconstrucción de los principios de la Ilustración, aplicados a una sociedad cosmopolita mediante la práctica del poder comunicativo de los ciudadanos que, suponemos, producirá el desencadenamiento de las libertades comunicativas en el horizonte teórico propuesto por Habermas.

Palabras clave: Estado nacional; soberanía; globalización; sociedad cosmopolita; democracia; comunicación.

\begin{abstract}
According to the definition presented by Hans Kelsen in his legal thinking classic work General Theory of Law and State, National State is a political organization that a national community creates to exercise political power within a valid legal order framework for a delimited territorial space, where the principle of peoples' self-determination is guaranteed with a required complement: sovereignty. However, due to globalization processes, particularly, market-based economy, the most important decisions affecting the State are made by international economy entities such as the International
\end{abstract}


Monetary Fund or the World Bank. In that way, self-determination and sovereignty principles, part of the classical definition of National State, are called into question and have become just fiction. When facing that reality, the idea of a cosmopolitan society postulated by Kant more than two hundred years ago, brings back its validity, but now, due to its historical distance, Kant postulation must be implemented for democratizing the process towards a new world order constitution. This article explores the possibility to strengthen democracy by rebuilding The Illustration principles applied to a Cosmopolitan society through citizens' practice of communicative power, which are supposed to trigger communicative liberty in the theoretical horizon proposed by Habermas.

Key words: National state, sovereignty, globalization, cosmopolitan society, democracy, communication. 


\section{INTRODUCCIÓN}

La política del Estado nacional está desbordada a causa de los problemas surgidos a nivel mundial y también de los problemas interiores. Hay situaciones de conflicto social que no se pueden abordar desde las limitadas perspectivas nacionales: el paro laboral, la segmentación de la sociedad (guetos, criminalidad, desamparo, abandono), problemas de inmigración, desequilibrio ecológico y movimientos sociales de diversa índole.

El poder del Estado nacional se ha erosionado ante la globalización, la cual, a la vez, es suma y efecto de la emergencia de nuevas tecnologías de información, del avance de los sistemas financieros, de la descentralización de los núcleos de poder y de los movimientos sociales de carácter transfronterizo. Las decisiones que tienen que ver con la política interior de los Estados se toman hoy en instancias transnacionales como el Banco Mundial y el Fondo Monetario Internacional; de tal manera que, las reformas políticas a nivel nacional no son, en el mejor de los casos, más que adaptaciones de las órdenes emanadas del aparato burocrático de aquellas entidades financieras, las cuales, dicho sea de paso, no se caracterizan precisamente por ser democráticas. Ante este hecho, surge la pregunta relativa al ámbito de lo político: ¿qué participación efectiva tienen los pueblos en la configuración autónoma de sus destinos?

El nuevo orden mundial se ha configurado a la medida de la sociedad de libre mercado. Las consecuencias de este proceso son funestas tanto para el medio ambiente natural como para la configuración misma del ordenamiento social. Frente a esta situación, se impone como deber la acción humana lúcida y reflexiva con miras a instituir un mundo distinto y mejor que el que tenemos, toda vez que la autonomía individual y colectiva se concreta en el hecho de poder intervenir racionalmente en la configuración de nuestro destino social.

Dado el abandono del mundo social y natural a la lógica del mercado, se plantea como alternativa el retorno de lo político. Del proceso conflictivo de tránsito de las sociedades multiculturales y transnacionales debe surgir una nueva forma de integración social que sobrepase las fronteras y posibilidades del Estado nacional; un convincente orden político que, más allá de todas las diferencias subculturales, motive al ciudadano a responsabilizarse del todo social.

El punto de partida de esta reflexión es el siguiente problema: ante el desbordamiento del Estado nacional producido por la globalidad, ¿es posible 
un ordenamiento político de carácter mundial? ¿Cuáles serían sus características? ¿Qué retos debe enfrentar? ¿Sobre qué forma de gobierno debe ser sustentado? ¿Qué problemas contribuiría a resolver?

Este trabajo se propone mostrar que, ante el fenómeno de la globalidad que se manifiesta fundamentalmente como "globalización"-, el poder de los Estados nacionales se está desvaneciendo, ha convertido la soberanía nacional en una mera ficción; por lo cual, se torna imperativa la creación de un nuevo orden político mundial sobre la base de la democratización de la sociedad universal.

Con el fin de alcanzar este objetivo, (1) se parte del concepto de Estado y de sus elementos, según la teoría de Hans Kelsen, para destacar el principio de territorialidad y de soberanía; (2) se pone de manifiesto que el Estado moderno cumplió su misión histórica pero que hoy se encuentra desbordado por los procesos de globalización; (3) lo anterior implica trabajar por la institución de una sociedad cosmopolita en el horizonte del planteamiento kantiano de la "Paz perpetua"; (4) dicho planteamiento se implementa ahora, a la distancia histórica de doscientos años, por la democratización de los procesos de constitución de un nuevo orden mundial. En síntesis, se trata de definir la democracia como método, exponer los principios de una democracia radical y destacar el valor del pluralismo como fuente misma de la democracia en una sociedad multicultural.

\section{La IDEA de Estado moderno Según la filosofía del Derecho}

Resulta sintomático que, para referirse a una sociedad jurídicamente organizada, los teóricos contemporáneos prefieran hablar de "ordenamiento político" en general, en vez de "Estado". El concepto de ordenamiento político describe mejor a una sociedad que sobrepasa las estrechas fronteras del Estado nacional y que, sin embargo, no puede existir sin un conjunto de normas e instituciones que regulen las relaciones entre los asociados. Bajo el concepto de "Estado nacional" se designaba a un tipo comunidad determinada, localizada espacial y temporalmente, organizada conforme a leyes y reconocida, tanto en el interior como en el exterior, gracias a los principios de territorialidad, soberanía y nacionalidad. Empero, ese Estado moderno hoy no es más que una ficción. Debido a la dinámica acelerada de la globalización por la economía de mercado, los conflictos sociales han perdido su carácter local y se han tornado mundiales, reclaman soluciones que sobrepasan los marcos cada vez más estrechos de la soberanía nacional y erosionan la base conceptual misma del Estado. 
En Teoría general del Derecho y del Estado Hans Kelsen (1958) define el Estado como "organización política, porque es un orden que regula, monopolizándolo, el uso de la fuerza" (p. 224). Destaca en su caracterización la definición de "orden jurídico", como idea a la cual los miembros de una sociedad ciñen su comportamiento; de "organización política", que crea una comunidad nacional ("por oposición a una internacional"); del "uso coercitivo de la fuerza", como expresión del poder político que se reconoce como derecho; y, finalmente, el sentido social del Estado, entendido aquí como poder posible dentro del marco de un orden normativo como regulador de la conducta humana. El Estado es, en síntesis, una comunidad organizada según normas que regulan las relaciones entre los asociados.

Así las cosas, esta caracterización general recoge los elementos definitorios de la justificación jurídica y de la necesidad histórica del ordenamiento político, que posibilita el tránsito del "estado de naturaleza" al estado de "comunidad política" de la sociedad. Desde el punto de vista de los elementos que conforman ese orden jurídico, las características esenciales del Estado moderno, en su versión clásica, son, de un lado, la territorialidad y, de otro, la libre autodeterminación que implica la soberanía.

En efecto, entre los elementos peculiares y distintivos de la forma "Estado", Kelsen señala "el territorio del Estado" y lo define como el ámbito espacial del orden jurídico, porque si los Estados no tuvieran fronteras fijas, no podrían coexistir sin entrar en conflicto. Si bien es cierto que la Teoría general del Derecho y del Estado considera la existencia de un orden jurídico internacional, cuya función es determinar y limitar entre sí "los ámbitos espaciales de validez de los órdenes jurídicos nacionales", este tiene solo un carácter normativo, regulativo, no coactivo frente al Estado como tal. Podría pensarse que el carácter territorial del Estado, según la definición de Kelsen, queda atenuado con la advertencia, según la cual, "la unidad territorial del Estado es una unidad jurídica, no geográfica natural" (Kelsen, 1958:248). Sin embargo, para los efectos materiales de jurisdicción y soberanía, el orden jurídico del Estado solo tiene validez dentro de un marco geográfico delimitado a las fronteras territoriales o dentro de los territorios (insulares o transterritoriales), sobre los cuales, el orden político así concebido, efectivamente, se aplica. Con esto, se espera dar relevancia al aspecto, que para los efectos de este trabajo queremos destacar; a saber, el Estado como un orden jurídico que tiene validez dentro un espacio territorial bien delimitado. 
El otro elemento del Estado, sobre el cual se quiere llamar la atención, es el principio de la autodeterminación y su complemento necesario, la soberanía. La idea de autodeterminación está relacionada con la de libertad, la cual se desarrolla como tránsito de la libertad del "estado de naturaleza" a la "libertad política" o libertad social, producto del contrato entre los individuos. Si la primera es entendida como el derecho de cada uno a disponer de la voluntad a su arbitrio, la segunda es la condición histórica necesaria por la que los hombres renuncian al reino ilimitado de su "apetito" y se obligan a entrar en sociedad en aras de su propia seguridad y existencia. La libertad política es la unidad de la voluntad individual y de la colectiva, que toma la forma de autodeterminación bajo la forma de Estado. Se crea así un orden normativo que confiere al Estado el carácter de autoridad suprema, como derecho de expedir mandatos obligatorios, y con la fuerza necesaria para hacerlos cumplir: "Atribuir soberanía a un Estado significa que tal Estado constituye la suprema autoridad por encima y más allá de la cual no puede existir una superior que regule y determine su existencia" (Kelsen, 1958:400). La autodeterminación y la soberanía han devenido como práctica, según la cual, el orden llamado Estado es dueño y señor de su destino dentro del marco de su jurisdicción sin admitir ningún otro dictado que el que se da a sí mismo.

Pues bien, el principio de territorialidad y, sobre todo, el principio de autodeterminación y su complemento, la soberanía, son lo que hoy está puesto en cuestión ante la realidad de la globalidad que supera el ámbito de decisión puramente regional de los Estados. Si a los principios mencionados se agrega la hoy muy dudosa nacionalidad - habida cuenta de la identificación entre Estado, nación y ciudadanía - el ordenamiento que se conoce como Estado nacional será horadado en su base conceptual misma y amenazará ruina frente a los nuevos retos que, planteados a escala global, desbordan las fronteras territoriales y la supuesta autodeterminación de los pueblos. El Estado nacional se ve desafiado en el interior por el multiculturalismo y, desde el exterior, por el proceso de globalización.

\section{LA FICCIÓN DEL ESTADO NACIONAL Y LA GLOBALIZACIÓN}

La globalización es un proceso caracterizado por la influencia recíproca entre eventos, que ocurren a escala regional, y otros que acontecen en lugares muy distantes. Las comunicaciones hoy extienden sus redes a escala planetaria mediante los "lenguajes naturales" (medios electrónicos) o los "códigos especiales" (el dinero y el Derecho). El crecimiento de las comunicaciones, si bien aumenta los contactos entre lugares distantes, no provoca per se una 
concatenación discursiva que favorezca los espacios de discusión y debate propios de los asuntos públicos (Habermas, 1999).

El Estado nacional cumplió, en su momento, de manera convincente, con su compromiso histórico. De una parte, posibilitó formas más o menos efectivas de organización de la esfera pública; y de otra, reguló la política económica relacionada con las tres funciones básicas que debía controlar: producción, distribución y consumo. En la actualidad, nos hallamos ante el desafío de la globalización de la economía, de las tecnologías, del armamentismo y de los riesgos ecológicos. Estos problemas no pueden solucionarse dentro del marco del Estado nacional. La desnacionalización de la economía ha llevado a los países a proponer soluciones transfronterizas para sujetar al cíclope. Así, se han implementado políticas de mercado común en Europa, Norteamérica, Asia y Sudamérica. Simultáneamente, se han tratado de promover formas transnacionales de organización política, que contribuyan al fortalecimiento y operatividad eficaz de asociaciones del tipo Organización de las Naciones Unidas.

Los procesos de globalización llevan a hablar hoy de "sociedad mundial", dado que los sistemas de comunicación y los mercados han establecido un conjunto global. En realidad, se debe hablar de una sociedad mundial estratificada porque la lógica del mercado mundial vincula la productividad progresiva con depauperación creciente y, en general, procesos de desarrollo con otros de subdesarrollo: la globalización escinde al mundo y a la vez lo compele, en cuanto a comunidad de riesgo, a actuar de manera cooperativa.

Tal como lo ha hecho notar Norbert Bilbeny (1999) en Democracia para la diversidad, la globalización comporta un lado positivo si se toman en consideración los valores implícitos en la globalidad: la conciencia de que, como los grandes problemas son comunes a la humanidad, su solución depende del trabajo mancomunado de la sociedad mundial, a través del reconocimiento de los derechos básicos, de la aceptación de la identidad cultural que respeta las diferencias y de la ampliación de la participación, gracias a la innovación informática y a la interactividad que permite la reciprocidad entre personas y culturas.

¿Es posible en el mundo de la globalización fundar un espacio para lo político? ¿O los seres humanos estamos destinados al repliegue en la esfera privada, a funcionar como un mecanismo más de una enorme organización mecánica diseñada según el sistema de mercado? No en vano, hay quienes 
pretenden hoy en día que la sociología se haya superado y en su lugar se haya instaurado una "ingeniería social". Según esto, la humanidad estaría destinada a regirse por la lógica de una concatenación invisible que, a través del modelo de sistemas, opera como una máquina en la cual cada uno tiene su lugar. ¿En dónde queda, entonces, la autonomía individual y colectiva? Si los seres humanos podemos influir de manera lúcida y reflexiva en nuestros destinos, se espera que pueda ser instituido un orden social y económico distinto de carácter mundial, apoyado en la capacidad de acción de los organismos internacionales, en procesos de "sintonización entre regímenes regionales que hoy están surgiendo en el marco, y bajo la presión, de una sociedad movilizada en términos mundiales" (Habermas, 1997:183).

La globalización ha traído, algunas consecuencias negativas, entre otras, la exclusión social y cultural y un crecimiento ilimitado que comporta riesgos ecológicos, consumismo y uniformización de las conductas, así como un individualismo masivo. Sin duda, donde más se notan los efectos nefastos de este proceso es en la esfera económica: un gran sector de la sociedad ha quedado segmentado por la depauperación. Sin embargo, "segmentación no significa que una sociedad pueda quitarse de encima sus partes sin más consecuencias" (Habermas, 1997:183). El empobrecimiento creciente de un vasto sector de la sociedad genera violencia por las tensiones sociales, la pérdida de bienestar de ciertos grupos que ven amenazada su seguridad y sus privilegios por la acción delictiva de los marginados y una peligrosa regresión hacia ideologías nacionalistas, que exacerban los brotes de xenofobia frente al desesperado "desquite" de los inmigrantes.

Otro de los efectos negativos de la globalización es el consumismo y la individualización masiva; vivimos, como dice Cornelius Castoriadis (1997), en la época del "conformismo generalizado". El dinero y el consumo se han convertido en los fines propios de la humanidad y el individualismo ha replegado al sujeto al ámbito de la esfera privada. El ideal de este tipo de vida se manifiesta en la publicidad bajo la trivialidad del "gane dinero y consuma". ¿Es posible que una sociedad pueda seguir funcionando y reproduciéndose sobre esta única base? Los efectos de la mediatización de la sociedad, producidos por las redes electrónicas, han hecho que cada vez más los individuos se encierren en su rincón solitario, sin ningún interés por los asuntos públicos. La televisión también conspira contra el ideal político. Hoy los sujetos pasan horas y horas frente a un aparato que no exige de ellos sino recepción pasiva de innumerables estímulos, que lo único que transmiten es invitación 
al consumo y a la banalidad, sin hablar del empobrecimiento del lenguaje, que de allí deriva, porque ya nadie se comunica con nadie.

Ante esta realidad, se precisa una "creación imaginaria" que dibuje en el horizonte de la vida humana otras significaciones que no sean las del consumo y de la ilimitada de la producción y que complementariamente posibiliten formas de vida diferentes que puedan ser entendidas por los seres humanos como algo que vale la pena: debemos querer una sociedad en la que el dinero y el consumo no sean los valores centrales, en la que la economía sea un medio para la vida humana y en la cual renunciemos a esta loca carrera del consumo cada vez mayor.

Como se ve, la globalización no solo comporta las posibilidades implícitas en la globalidad, sino también aspectos negativos que deben ser enfrentados hoy desde perspectivas mundiales. Interesa resaltar que existen problemas que ya no se pueden resolver a escala regional dentro del marco del Estado nacional, pues este está desbordado por la globalización y por sus propios problemas internos. "El vaciamiento de la soberanía nacional seguirá ahondándose y por tanto, resulta imprescindible proseguir con la ampliación de las facultades de acción política a nivel supranacional" (Habermas, 1997:175). El Estado moderno dio un ejemplo histórico en lo que a integración social se refiere; si este tipo de organización jurídica de las relaciones sociales hoy está desbordado, no significa que deba abandonarse el ideal de un ordenamiento político; sobre todo, debe tenerse presente que el "nuevo ordenamiento no necesariamente debe identificarse con la forma conocida como Estado" (Bilbeny, 1998:2020).

\section{EL IDEAL COSMOPOLITA COMO IDEA REGULATIVA DE LA RAZÓN}

Según Kant, una forma de orden cosmopolita es posible por la creciente interdependencia de los pueblos y el avance gradual del espíritu de ilustración. La sociedad cosmopolita es posible, puesto que hay indicios para sentir atracción por la idea racional, según la cual, el desarrollo de todas las facultades de la naturaleza humana exige la búsqueda de una política perfecta, es decir, un orden cosmopolita, universal.

En los escritos de Kant sobre la sociedad y la historia, subyace la idea una humanidad que progresa hacia un mundo mejor. El filósofo de Könisberg no tiene una concepción muy optimista de la naturaleza humana, pues se refiere al hombre como un ser tallado de una madera retorcida; un vistazo al 
panorama histórico lleva a tener una idea pesimista del género humano, por todas partes la maldad se afana y no se sabe con certeza que opinión tener de una especie en la que predomina la vanidad, el afán de poder, la envidia y la competencia. Empero, esta "insociable sociabilidad del hombre" es un ardid de la naturaleza para el despliegue de los talentos humanos que de otra forma permanecerían latentes. Kant no concibe una sociedad armónica, sin conflictos - "la naturaleza quiere discordia"-, sino una sociedad que avanza hacia formas de organización en la que los conflictos puedan solucionarse sin acudir a la guerra. En aras del progreso en la esfera moral y en la jurídica, es posible una sociedad cada vez mejor y distinta.

Kant (1964) pregunta, ¿cómo podemos saber si el género humano se halla en progreso hacia lo mejor? No se trata de la historia natural del hombre sino de su historia moral, referida al género humano en tanto concepto universal. Puede saberse sobre el futuro en la medida en que es posible una exposición a priori de la historia, "si el profeta hace y dispone los acontecimientos que anuncia de antemano" (p. 191). Para Kant, es claro que la cuestión del progreso no puede resolverse directamente por la experiencia porque se trata de la predicción de acciones libres. Sin embargo, se podría buscar en la experiencia fenoménica algún acontecimiento que sirva de indicativo, como prueba de la tendencia moral del género humano. Kant ve en un hecho de su tiempo, en la Revolución francesa, un grandioso impulso del que infiere una disposición y facultad del género humano hacia lo mejor, que prueba que "en principio, tiene que haber un elemento moral que la razón pone ante los ojos como puro" (p. 199). El pueblo se auto instituye como "derecho" y al mismo tiempo descubre un fin incondicionado que se impone como deber, el deber de hacer la paz: "afirmo que el género humano logrará esa meta y también que los progresos hacia lo mejor ya no retrocederán completamente" (1964:200). La Ilustración será la encargada de afirmar los progresos conseguidos mediante la evolución constitucional.

Kant (1964) tiene en mente una constitución en la cual "los que obedecen la ley sean al mismo tiempo legisladores", y la comunidad que se adecua a ella es un "ideal" que acaso nunca podrá alcanzarse completamente; no obstante, tiene el valor de servir de guía para la acción: "no es una hueca quimera sino la eterna norma de cualquier constitución civil en general y el alejamiento de toda guerra". La sociedad organizada constitucionalmente es un ejemplo fenoménico de progreso moral, entrar en ella constituye un deber. "Si debo, 
puedo", es el postulado de la historia expresado por el filósofo: es un deber de la humanidad buscar caminos posibles para afianzar la esperanza de un mundo mejor.

Las relaciones entre los hombres se organizan según la constitución civil: bien sea como ius civitas (derecho político de los individuos en una comunidad), como ius gentium (de los Estados en sus relaciones mutuas), o como ius cosmopoliticum (de los ciudadanos en un ordenamiento político universal). Esta división no es arbitraria, sino necesaria en relación con la idea de la "paz perpetua". El único medio para salir de la guerra permanente entre los Estados, aquellos que se encuentran en sus relaciones mutuas como en un estado de naturaleza, es la institución de leyes públicas coactivas.

Lo anterior plantea la idea de una república universal pero, si ello no es posible, asimismo propone la idea de una federación "sin que los Estados deban por esta razón, someterse a leyes públicas y a su coacción" (Kant, 1994:24).

Para mostrar la posibilidad de un Derecho cosmopolita, Kant menciona dos planteamientos: a) toda violación del derecho "en un punto de la tierra repercute en todos los demás" y, b) el poder del dinero, producto del creciente espíritu comercial, inclina a los hombres hacia relaciones pacíficas. Dentro del marco histórico de su época, no podía prever que tanto la necesidad de una defensa de los derechos humanos como la globalización de la economía, que desborda los límites del Estado nacional, imponen hoy no solo una federación de Estados, sino un nuevo orden político mundial con fuerza coactiva no ya en relación con los ciudadanos de una comunidad particular (el Estado), sino como ciudadanos del mundo (sociedad cosmopolita). La comunidad postnacional implanta la necesidad de crear una forma de ordenamiento de carácter universal basada no solo en la buena voluntad, sino en la fuerza del Derecho. "El hombre está obligado a ser un buen ciudadano, aunque no está obligado a ser moralmente bueno" (Kant, 1994:38). Pero, hay siempre en el hombre una tendencia, aunque latente, a la virtud; la razón crece continuamente al aumentar la cultura, con la que también aumenta la culpabilidad por las transgresiones.

Este progreso del género humano hacia lo mejor aportaría importantes resultados: al decir de Kant, los hombres se harían más buenos, se incrementaría la obediencia a las leyes, habría menos discordias en los procesos, mayor seguridad en la palabra comprometida... Hasta llegar a una sociedad cosmopolita. 
Esperar que un producto de creación política tal como aquí lo pensamos se cumpla algún día, por remoto que fuese, constituye un deleitoso ensueño; pero el pensamiento de una aproximación a esas constituciones con el convencimiento de que puedan existir en tanto estén regidas por leyes morales, no solo es un deber del ciudadano sino también del gobernante (Kant, 1964:207).

La piedra de toque de la legislación es la buena voluntad del sujeto que se expresa en el imperativo "obra de tal manera que tu máxima pueda convertirse en ley universal". El Derecho legisla acciones, pero no legisla intenciones; las leyes jurídicas moldean exteriormente la conducta de los hombres "lo mismo que si no tuvieran malas inclinaciones". Pero, si no existe la inclinación moral conforme a la idea del "deber", la norma solo es patológica; en cambio, la adhesión a un concepto del deber por el deber mismo, sin tomar en cuenta la reciprocidad, es moral. El lector excusará este rodeo que hemos tomado, pero lo creemos necesario puesto que en esta idea se funda el concepto de autonomía individual y colectiva, tan importante para la acción democrática.

La idea kantiana, según la cual la libertad debe ser entendida como obediencia a la ley a la cual he dado mi consentimiento, es el principio de una constitución en la que, los que obedecen la ley deben ser al mismo tiempo legisladores. Este planteamiento se materializa en la constitución republicana, forma de Estado en el que la reparación del poder ejecutivo y del poder legislativo garantizan que el legislador no puede ser al mismo tiempo el ejecutor de su voluntad; por tanto, toda forma de gobierno "debe ser representativa". El filósofo descarta la democracia por considerarla como un "despotismo" en el que "todos quieren ser soberano" y se inclina por formas autocráticas o aristocráticas de republicanismo.

A la distancia histórica de doscientos años de La paz perpetua, podemos advertir que la democracia es, entre otras formas de ordenamiento político, la que más se acerca a la autonomía individual y colectiva implícita en el ideal regulativo de una sociedad cosmopolita.

\section{LA DEMOCRACIA COMO PROCEDIMIENTO}

Una vez más, Hans Kelsen (1988) nos sirve de guía en nuestra disertación. La característica esencial de la democracia es la participación de la comunidad en el gobierno, es decir, en la institución de las leyes que regulan el comportamiento de los asociados. Destaca el carácter procedimental de la democracia entendida como "método político por medio del 
cual el ordenamiento social es creado y aplicado por quienes están sujetos a ese mismo ordenamiento, de forma que esté asegurada la libertad política en el sentido de autodeterminación" (p. 211).

Históricamente se ha definido la democracia como gobierno del pueblo y para el pueblo. Empero, si bien todo gobierno es para el pueblo, no todo gobierno es del pueblo: Un gobierno para el pueblo puede ser cualquier tipo de gobierno. Las relaciones históricas entre liberalismo y democracia no son necesariamente de compatibilidad, como lo ha hecho notar Norberto Bobbio (1992). Si bien es cierto que los valores básicos de la democracia son la libertad y la igualdad, no todo liberalismo es democrático (tal es el caso de regímenes que defienden estos valores, de manera peculiar, bajo gobiernos autocráticos), ni todo sistema que se presenta como democrático es liberal (el nacional-socialismo, por citar un caso), aunque corrientemente coincidan liberalismo y democracia. En cualquier caso, la idea fundamental es la libertad política.

Si como lo muestra la filosofía política clásica, la transición de la llamada "libertad natural" a la libertad política es el inicio de la sociedad ordenada, según leyes que regulan las relaciones entre los asociados y dejan atrás el arbitrio del capricho y del deseo de cada cual (libertad en la anarquía) para estar bajo el imperio de la ley social (libertad de la democracia), esto significa la posibilidad de estar bajo un orden normativo en cuya institución el sujeto participa con el interés de garantizar su libertad individual como miembro de un todo social. ¿Ninguna sociedad puede existir sin normas?, en consecuencia, "si no podemos dejar de estar dominados", entonces, ¿podemos querer "ser dominados por nosotros mismos?" (Kelsen, 1988:231).

\section{RETOS DE LA DEMOCRACIA}

La democracia como método de ordenamiento político no es perfecta, es más bien una realidad en marcha, una creación continua; a su vez, es también el procedimiento más acorde con la autonomía individual y colectiva. Nuevas formas de conflicto retan a la democracia: la gran escala de la vida moderna, la creciente burocratización de las estructuras políticas, la índole cada vez más técnica de las decisiones que tiene que afrontar, la tendencia de la sociedad civil a convertirse en una sociedad de masas, el cambio tecnológico, el fuerte centralismo de las instituciones económicas y los contactos multiculturales debidos a la migración o a la capacidad de establecer contactos mediante redes de comunicación planetarias. Estos retos, al mismo tiempo 
que la potencian, tienden a entorpecerla. En un mundo de contactos transnacionales y transculturales hay quienes aspiran a recrear un "pasado valioso" o a fusionar el pasado y el futuro, lo nacional y lo transnacional, mediante la invocación de regímenes autocráticos.

El desafío de recrear la democracia en un mundo emergente de toma de decisiones transnacionales es serio. ¿Podrá servir el desarrollo de los medios de comunicación, el impacto cultural de la televisión, la organización de la economía en instituciones internacionales para hacer frente al desafío?, ¿se podrá hacer uso de las tecnologías de comunicación para organizar los pueblos transnacionalmente? No sabemos, pero debemos esperarlo y hacer que sea posible.

La globalización es el mayor reto que hoy debe enfrentar la democracia: la división entre países ricos y países pobres no había sido nunca tan extrema; el fenómeno de la inmigración ha revitalizado el nacionalismo y todas las formas de exclusión; el poder del Estado nacional se erosiona frente a la globalización económica. Las entidades económicas transnacionales (Fondo Monetario Internacional y Banco Mundial) dan las órdenes que han de ser implementadas por los gobiernos de los distintos países, frente a lo cual, surge la pregunta ¿qué participación efectiva tienen los pueblos en la configuración de sus destinos? "La estructura transnacional de las fuerzas económicas y políticas que están surgiendo con rapidez es muy posible que exacerbe las tensiones en torno a los problemas de identidad" (Markoff, 1996:202).

\section{Democracia RADical}

En vista de las dificultades que obstaculizan la democracia tanto a nivel interno (en el marco cada vez más obsoleto del Estado nacional), como a nivel externo (a propósito del avance de la globalización), hay quienes critican el proyecto democrático y como alternativa proponen la autocracia bajo la forma de liberalismo estamental o cualquier otra forma de organización política.

De otra parte, algunas personas piensan que la democracia se desarrolla con más democracia y proponen la fórmula de la democracia radical.

En cuanto a los primeros, basta advertirles que busquen en los recuerdos de la historia la experiencia que ha dejado la huella de los regímenes autocráticos. decía que nada tenemos que aprender de la historia porque cada época corresponde al estado de desarrollo de un pueblo y en cada caso es el genio individual el que sabe hacer lo correcto. No obstante, creemos que 
bien puede buscarse en el pasado todo aquello que sea digno de imitarse, incluidas las experiencias negativas, es decir, "los desengaños que en el futuro tratamos de evitar" (Habermas, J., 1997, p.73). La experiencia de los regímenes totalitarios nos conduce a sacar lecciones del "estado panóptico"; como contrapartida, debe establecerse un ordenamiento político que garantice a todos los ciudadanos igual autonomía individual y colectiva.

La fórmula de la democracia radical parece más convincente. Chantal Mouffe (1999) dice: "Hemos de avanzar de la democratización del Estado a la democratización de la sociedad y la tarea consiste en luchar contra el poder autocrático en todas sus formas, a fin de infiltrarse en los espacios todavía ocupados por centros de poder no democráticos" (p. 133). Independientemente del carácter de "consigna" que pueda tener esta formulación, creemos que es susceptible de desarrollos tanto teóricos como prácticos efectivos. En efecto, Habermas propone dos métodos de desarrollo del procedimiento democrático. El primero es el "modelo del asedio" del poder burocrático por el poder comunicativo de los ciudadanos, opuesto a la representación clásica de la revolución como conquista y destrucción del poder coercitivo estatal. De esta manera, las desencadenadas libertades comunicativas de los ciudadanos han de hacerse efectivas en el uso público de la razón. Según este modelo, los ciudadanos, por medio de debates públicos tratan de ejercer influencia sobre los procesos de deliberación y decisión, pero sin intención de "conquistar la fortaleza".

El segundo es llamado "modelo de las esclusas". El sistema político cuenta con un centro y una periferia; para que los ciudadanos puedan ejercer influencia sobre el centro (parlamento, tribunales, administración), los flujos de comunicación procedentes de la periferia han de pasar las esclusas de los procedimientos democráticos y de los que el Estado de derecho comporta. El modelo de las esclusas cuenta con una democratización más profunda que el modelo del asedio; todas las decisiones que afecten a la comunidad pueden ser discutidas por los interesados ante foros ampliados de crítica racional: "en la democracia los expertos no pueden tener ningún privilegio" (Mouffe, 1999:151).

En el procedimiento democrático es indispensable la acción, la cual es indisociable de la palabra, en la medida en que ser ciudadano implica el ejercicio efectivo de la actividad política; la democracia conlleva participación, opinar no es suficiente, actuar es necesario, poder actuar en aquello que al ciudadano le interesa en todos los ámbitos de la vida pública (Bilbeny, 1996). Empe- 
ro, una sociedad justa presupone no solo asegurar los derechos y libertades subjetivas de acción, sino también las condiciones materiales elementales para hacer un uso efectivo de esos derechos y libertades. Como solía decir Estanislao Zuleta, "es casi una burla para la población decirle que todos somos libres e iguales ante la ley si no los somos ante la vida". Por eso, la democracia puede verse seriamente amenazada en virtud de las desigualdades económicas y las asimetrías sociales que crean formas de dependencia y exclusión concretas entre los individuos. Una política de la libertad debe ser implementada con una política de la igualdad, es decir que todos los miembros de la sociedad deben tener condiciones sociales y económicas que hagan viable la realización de una vida humana digna (Cortés, 1999).

\section{Democracia y PluRalismo}

La tesis central que sostiene Chantal Mouffe en El retorno de lo político es que todo el tema de la democracia gira alrededor del pluralismo: la diversidad de opiniones y el antagonismo entre diferentes tendencias es el terreno propio de los políticos. No puede aspirarse a la institución de una sociedad. homogénea, porque eso sería imposible y monstruoso a la vez. Si se lograra homogenizar la sociedad, se acabaría con el núcleo mismo de nuevas formas de vida y de institución de lo social. Esto resulta imposible porque, como ya lo mostró el psicoanálisis, ni siquiera el sujeto singular está en armonía consigo mismo: es contradicción, ambivalencia, complejidad. De acuerdo con Zuleta (1991), el pluralismo hay que aceptarlo no como un mal menor o una fatalidad inevitable, sino como aquello que enriquece la vida y obliga al hombre a desarrollar sus talentos y competencias racionales para estar a la altura de sus posibilidades. Si la democracia es el procedimiento que permite llegar a acuerdos relativos a través de la discusión y el debate, halla en la pluralidad de opiniones su esencia, su sentido y su existencia misma. Los consensos logrados a través del debate democrático son acuerdos parciales $\mathrm{y}$ fuente de nuevos temas y formas de discusión en un proceso de cuestionamiento sin término relacionado con la institución efectiva de la sociedad.

De igual manera, Zuleta afirmaba que la democracia descarta la posibilidad de una sociedad armónica, sin conflictos; pretende, en cambio, una sociedad con mejores conflictos porque mejores serán las formas de solucionarlos sin recurrir a la violencia o a la descalificación del otro o a su aniquilamiento. La unanimidad querida por los autoritarismos o totalitarismos solo puede ser lograda mediante la servidumbre. La democracia constituye y asegura la existencia de un marco legal, dentro del cual pueda ejercerse el derecho a 
ser diferente, a tener opiniones distintas que permitan que la diversidad de ideales de vida, de formas culturales y pluralidad de pensamientos puedan desarrollarse sin que se degenere en violencia o en modos de descalificación. Esto posibilita la vigencia de formas legales que impidan la agresión, exclusión o aniquilamiento de quienes tienen intereses distintos u opuestos. El entendimiento intersubjetivo es fundamento de la democracia y alternativa a la violencia, mediante la acción comunicativa, en la cual, la única fuerza aceptable es la "coerción sin coerciones que produce el mejor argumento".

La democracia comprende no solo el derecho a pensar por sí mismo — que es al mismo tiempo un deber-, sino también el deber de escuchar al otro (Bilbeny, 1999). Una característica del discurso autoritario consiste en que el emisor no puede imaginarse siquiera que el otro piense distinto de él; se comporta como si todos los que no piensan como él estuvieran "locos" o fueran sus enemigos. Característico de la personalidad democrática es el reconocimiento de que el opositor también puede tener razón; se trata de hacer un esfuerzo para determinar hasta qué punto se puede aprender del otro, en un movimiento que va contra toda discriminación, contra el racismo, la xenofobia y toda forma patológica de exclusión. "Ponerse en el lugar del otro" es la segunda máxima del racionalismo expuesta por Kant; el pluralismo la amplía al considerar a ese otro no como individuo solamente, sino como cultura. Escuchar implica el reconocimiento de que hay otros puntos de vista a través de los cuales, a lo mejor, se pueden entender cosas que desde nuestra perspectiva no logramos entender.

\section{Conclusión}

Hemos hecho un recorrido a partir del concepto de Estado tal como lo expone la filosofía política moderna; se ha descubierto que en la base del Estado se adhieren conceptos como territorialidad, soberanía y nacionalidad. Estos elementos constitutivos de la idea de Estado están en cuestión gracias al avance del proceso de globalización, toda vez que, en primer lugar, hay problemas que ya el Estado no puede resolver dentro de sus estrechos marcos espaciales (tanto en su dimensión jurídica como territorial); en segundo lugar, la globalización ha traído como consecuencia que las decisiones económicas fundamentales se tomen en centros burocráticos distantes y que los países (especialmente los del tercer mundo) se limiten a implementar las órdenes que emanan de aquellos organismos transnacionales; $y$, en tercer lugar, no se puede identificar Estado con nacionalidad porque hoy conviven dentro de un mismo país personas de diferentes lenguas, culturas, religiones, formas de 
vida e ideales. Las tres razones mencionadas nos han permitido hablar del Estado nacional como ficción.

La globalización comporta consecuencias negativas: ha aumentado la concentración de la riqueza y se ha incrementado también el número de pobres; el crecimiento ilimitado ha producido daños irreversibles en el ecosistema; la mediatización de la sociedad ha producido individualización masiva; el dinero y el consumo se han convertido en los objetivos más importantes cuando no los únicos - de la sociedad. Empero, la globalización comporta, como contrapartida, valores implícitos: la conciencia de que los problemas clave de las desigualdades sociales y los daños ecológicos deben ser resueltos por la humanidad en su conjunto; el reconocimiento de que los derechos fundamentales del hombre pueden ser garantizados mediante la institución de organizaciones internacionales que hagan más efectivos los mecanismos de imputabilidad jurídica; el aumento de las posibilidades de ilustración y participación democrática gracias a los lenguajes electrónicos; la conciencia de la multiculturalidad; y, la tendencia al pluralismo y al respeto de las identidades.

A partir del ideal cosmopolita propuesto por Kant en La paz perpetua, hemos planteado las posibilidades de un ordenamiento político de carácter mundial, en el que se destaca que este nuevo orden es viable a través del procedimiento democrático. Asimismo, hemos visto que la democracia tiene que enfrentar nuevos retos; sus posibilidades de acción y eficacia dependen de la democratización de todos los centros de decisiones que tienen que ver con los asuntos públicos. Se ha propuesto la fórmula de una democracia radical, que sigua los planteamientos de Habermas, y se ha manifestado que la democracia es el medio de hacer efectivo el "retorno de lo político", su vigencia y su existencia misma. De igual forma, se ha dicho que un sistema democrático depende también de la erradicación de las desigualdades económicas y sociales, porque de nada sirven los principios de libertad e igualdad cuando las asimetrías sociales persisten. Finalmente, se ha resaltado el valor del pluralismo y sus implicaciones en la tolerancia como medio para lograr una existencia humana digna dentro del respeto a la diferencia.

Las posibilidades de éxito del procedimiento democrático dependen en gran parte de la educación, cuya finalidad es formar individuos que se interesen por los asuntos públicos y que puedan convivir en el pluralismo y el respeto por la diferencia; individuos que sean "capaces de pensar por sí mismos", de "ponerse en el lugar del otro" y de "ser consecuentes", porque la democracia implica la aceptación de que, cuando estoy equivocado, debo cambiar. 


\section{REFERENCIAS}

Bilbeny, N. (1996). Europa después de Sarajevo. Claves éticas y políticas de la ciudadanía europea. Barcelona: Destino.

----- (1998). Política sin Estado. Barcelona: Ariel.

------ (1999). Democracia para la diversidad. Barcelona: Ariel.

Bobbio, N. (1992). Liberalismo y democracia. Buenos Aires: FCE.

Castoriadis, C. (1997). El avance de la insignificancia. Buenos Aires: Eudeba.

Cortés, F. (1999). De una política de la libertad a una política de la igualdad. Un ensayo sobre los límites del liberalismo. Medellín: Universidad de Antioquia.

Habermas, J. (1997). Más allá del Estado Nacional. Madrid: Trotta.

------ (falta la fecha). La inclusión del Otro. Barcelona: Paidós

Kant, I. (1964). Filosofia de la Historia. Buenos Aires: Nova.

----- (1994). La paz perpetua. Madrid: Tecnos.

Kelsen, H. (1958). Teoría general del Derecho y del Estado. México. UNAM.

----- (1988). Escritos sobre la democracia y el socialismo. Madrid: Debate.

Markoff, J. (1996). Olas de democracia. Madrid: Tecnos.

Mouffe, Ch. (1999). El retorno de lo político. Barcelona: Paidós.

Zuleta, E., (1991). "La participación democrática y su relación con la educación”. En: Colombia, democracia y derechos humanos. Bogotá: Altamir. 